\title{
Closed Fuel Cycle and Minor Actinide Multirecycling in a Gas-Cooled Fast Reactor
}

\author{
W. F. G. van Rooijen ${ }^{1}$ and J. L. Kloosterman ${ }^{2}$ \\ ${ }^{1}$ Nuclear \& Radiological Engineering, Georgia Institute of Technology, 801 Ferst Dr. NW, Atlanta, GA 30332-0405, USA \\ ${ }^{2}$ Radiation, Radionuclides and Reactors (R3) Department, Section Physics of Nuclear Reactors, Delft University of \\ Technology, Mekelweg 152629 JB Delft, The Netherlands \\ Correspondence should be addressed to W. F. G. van Rooijen, vanrooijen@mail.gatech.edu
}

Received 27 January 2009; Accepted 2 March 2009

Recommended by Guglielmo Lomonaco

\begin{abstract}
The Generation IV International Forum has identified the Gas-Cooled Fast Reactor (GCFR) as one of the reactor concepts for future deployment. The GCFR targets sustainability, which is achieved by the use of a closed nuclear fuel cycle where only fission products are discharged to a repository; all Heavy Metal isotopes are to be recycled in the reactor. In this paper, an overview is presented of recent results obtained in the study of the closed fuel cycle and the influence of the addition of extra Minor Actinide (MA) isotopes from existing LWR stockpiles. In the presented work, up to $10 \%$ of the fuel was homogeneously replaced by an MAmixture. The results are that addition of MA increases the potential of obtaining a closed fuel cycle. Reactivity coefficients generally decrease with increasing MA content. Addition of MA reduces the reactivity swing and allows very long irradiation intervals up to $10 \%$ FIMA with a small reactivity swing. Multirecycling studies show that a 600 MWth GCFR can transmute the MA from several PWRs. By a careful choice of the MA-fraction in the fuel, the reactivity of the fuel can be tuned to obtain a preset multiplication factor at end of cycle. Preliminary decay heat calculations show that the presence of MA in the fuel significantly increases the decay heat for time periods relevant to accidents $\left(10^{4}-10^{5} \mathrm{~s}\right.$ after shutdown). The paper ends with some recommendations for future research in this promising area of the nuclear fuel cycle.
\end{abstract}

Copyright (C) 2009 W. F. G. van Rooijen and J. L. Kloosterman. This is an open access article distributed under the Creative Commons Attribution License, which permits unrestricted use, distribution, and reproduction in any medium, provided the original work is properly cited.

\section{Introduction}

In 2002 the Generation IV International Forum introduced their vision of the future of nuclear power generation, proposing six reactor concepts which could be introduced from the 2050s [1]. One of the Gen IV concepts is the Gas Cooled Fast Reactor (GCFR). This reactor concept specifically targets sustainability by a combination of resource efficiency, efficient power conversion, and waste minimization. The GCFR has been investigated in the past, but the design requirements in those days did not allow a feasible design. The most stringent problem was the requirement of a high power density in the core for efficient breeding. In the Gen IV GCFR, the breeding mission is replaced by the requirement of "self-sustainability" in a closed fuel cycle: after an irradiation campaign, fuel is allowed to cool down, and subsequently all HM isotopes are recycled from the spent nuclear fuel. An appropriate amount of fertile material is added to make a new fuel loading for the same reactor. Only fission products (and inevitable reprocessing losses) go to a repository. The reactor should thus breed just enough excess fissile material to sustain itself. This choice reduces the requirements on core power density and reopens the way for GCFR concepts.

For the present work, investigations were carried out in the scope of the European GCFR-Specific Targeted REsearch Program STREP into the potential of adding extra Minor Actinide (MA, here considered to be $\mathrm{Np}$, Am, and $\mathrm{Cm}$ ) isotopes to the standard GFR600 fuel as a way to reduce stockpiles of MA materials. Both the plutonium and the MA are assumed to be available from legacy LWR Spent Nuclear Fuel, to be retrieved in the future by advanced reprocessing methods. It is a well-established fact that a significant reduction in repository requirements can only be achieved if the amount of MA in the repository is minimized. The fuel cycle option selected in the present work is very 
challenging. The homogeneous recycling of MA isotopes can cause several issues: the presence of MA isotopes in all parts of the fuel cycle poses a shielding problem; strong $\alpha$-emission in the fuel causes material issues; more issues are highlighted in [2]. The present work illustrates how an ideal closed fuel cycle could work.

This paper is organized as follows: some general remarks about transmutation are given in Section 2, followed by a presentation of the GFR600 design in Section 3, and the results of single-cycle transmutations in Section 4. The paper continues with a discussion of multirecycling calculations in Section 5 , followed by a discussion of decay heat calculations in Section 6. The paper closes with conclusions and recommendations for further research.

\section{The Influence of Actinide Isotopes on Reactor Performance}

In a closed fuel cycle, such as proposed for the Gen IV GCFR, there will inevitably be an accumulation of MA isotopes in the fuel. After an irradiation campaign, fuel is allowed to cool down, and is subsequently reprocessed, where all Heavy Metal (HM) isotopes are assumed to be refabricated into a new fuel loading. The fuel cycle target is to breed just enough fissile material during reactor operation so that the recycled fuel together with fertile material (U-238, usually) results in a new fuel with the same performance. Thus, MA isotopes with a sufficiently long half life will all be incorporated into the new fuel. By definition, MA isotopes remaining in the fuel are not very fissile, and admixing these isotopes to a nuclear fuel will generally decrease the reactivity of the fuel. As a measure of how an individual isotope influences the reactivity of the reactor, a reactivity weight $w_{i}$ is defined, which measures how the eigenvalue of a reactor changes if the number density of a particular isotope is perturbed. In previous work [3] the following expression was derived:

$$
w_{i} \equiv \frac{\Delta \rho}{\Delta N_{i}}=\frac{\left\langle\phi_{0}^{+},\left[\lambda_{0}\left(\partial P / \partial N_{i}\right)-\left(\partial L / \partial N_{i}\right)\right] \phi_{0}\right\rangle}{\left\langle\phi_{0}^{+}, P_{0} \phi_{0}\right\rangle} .
$$

In this equation, $P$ is the production operator of neutrons, $L$ is the loss operator, $\lambda$ is the eigenvalue of the reactor, $\phi$ is the forward flux, and $\phi^{+}$is the adjoint. Equation (1) can be derived in a straightforward manner using First Order Perturbation Theory. As an example, assume for instance an infinite, homogeneous medium with one group of neutrons. The operators $L_{0}$ and $P_{0}$ are given by

$$
\begin{gathered}
P_{0}=v \Sigma_{f}=\sum_{i=1}^{I} N_{i} \nu_{i} \sigma_{f, i}, \\
L_{0}=\Sigma_{a}=\sum_{i=1}^{I} N_{i} \sigma_{a, i},
\end{gathered}
$$

with the index $i$ running over all isotopes in the system. In the 1-group formalism, $\phi_{0}$ and $\phi_{0}^{+}$reduce to single numbers.
TABLE 1: Reactivity weights $\mathbf{w}_{\mathbf{i}}$ for several isotopes in several types of reactors, normalized to $\mathbf{w}_{\mathbf{i}}$ for Pu-239. Data sources: PWR based on EPR standard UOx fuel from [6], LMFBR based on a generic oxide fuel, sodium coolant [7], and GCFR based on GFR600 (described later in this paper).

\begin{tabular}{lccc}
\hline Isotope & LWR UOx & LMFBR & GCFR \\
\hline $\mathrm{U}-235$ & 0.392 & 0.759 & 0.785 \\
$\mathrm{U}-238$ & -0.007 & -0.049 & -0.067 \\
$\mathrm{~Np}-237$ & -0.507 & -0.111 & -0.159 \\
$\mathrm{Pu}-238$ & -0.360 & 0.662 & 0.660 \\
$\mathrm{Pu}-239$ & 1.000 & 1.000 & 1.000 \\
$\mathrm{Pu}-240$ & -3.847 & 0.134 & 0.120 \\
$\mathrm{Pu}-241$ & 1.485 & 1.418 & 1.484 \\
$\mathrm{Pu}-242$ & -0.462 & 0.081 & 0.064 \\
$\mathrm{Am}-241$ & -1.755 & -0.452 & -0.218 \\
$\mathrm{Am}-243$ & -0.802 & -0.153 & -0.192 \\
$\mathrm{Cm}-242$ & -0.028 & 0.429 & 0.418 \\
$\mathrm{Cm}-243$ & 1.787 & 2.374 & 2.481 \\
$\mathrm{Cm}-244$ & -0.192 & 0.219 & 0.214 \\
$\mathrm{Cm}-245$ & 3.032 & 2.013 & 2.125 \\
$\mathrm{Cm}-246$ & -0.020 & 0.150 & 0.145 \\
\hline
\end{tabular}

Taking the derivatives to $N_{i}$ in (2) and substituting in (1) results in

$$
w_{i}=\frac{\phi_{0}^{+}\left(\lambda_{0} \nu_{i} \sigma_{f, i}-\sigma_{a, i}\right) \phi_{0}}{\phi_{0}^{+} \nu \Sigma_{f} \phi_{0}}=\frac{1}{v \Sigma_{f}}\left(\lambda_{0} \nu_{i} \sigma_{f, i}-\sigma_{a, i}\right)
$$

which is similar to traditional definitions of reactivity weights as, for instance, found in [4]:

$$
w_{i}={\overline{v_{i}}}_{f, i}-\bar{\sigma}_{a, i}
$$

The differences between (3) and (4) are the presence of the factors $1 / \nu \Sigma_{f}$ and $\lambda_{0}$. These factors are not problematic, because $\lambda_{0}=1$ in a critical reactor, which is usually assumed in the derivation of (4), and $1 / v \sum_{f}$ can be removed by normalizing. Equation (1) can be evaluated by sensitivity analysis software, for example, the TSUNAMI-module in SCALE [5]. Reactivity weights calculated using (1) are given in Table 1 for a PWR with UOx fuel, an LMFBR, and a Gen IV GCFR. These weights are normalized to Pu-239.

Upon inspection of Table 1 some interesting properties are seen, for example, $\mathrm{Pu}-238$ is almost as good a fuel isotope as U-235 in a fast reactor. Furthermore, some isotopes which are net absorbers in a thermal reactor (e.g., Pu-240) are in fact less detrimental to a fast reactor. For actinide (multi-) recycling, the isotopes Np-237 and Am-241 are the most important, and these are net neutron absorbers, also in fast reactors. But this is not all bad news, because these isotopes 
transmute to $\mathrm{Pu}-238$, which is quite a good fuel for fast reactors, or to Am-242m, which is a highly fissile isotope:

$$
\begin{gathered}
{ }^{237} \mathrm{~Np} \underset{83 \%}{\stackrel{n}{\longrightarrow}}{ }^{238} \mathrm{~Np} \underset{99 \%}{\stackrel{\beta^{-}}{\longrightarrow}}{ }^{238} \mathrm{Pu}, \\
{ }^{241} \mathrm{Am} \underset{{ }_{71 \%}}{\stackrel{n}{\longrightarrow}}{ }^{242} \mathrm{Am} \underset{{ }_{83 \%}^{\beta^{-}}}{\stackrel{23}{\longrightarrow}}{ }^{242} \mathrm{Cm} \underset{99 \%}{\stackrel{\alpha}{\longrightarrow}}{ }^{238} \mathrm{Pu}, \\
{ }^{241} \mathrm{Am} \underset{13 \%}{\stackrel{n}{\longrightarrow}}{ }^{242 \mathrm{~m}} \mathrm{Am} .
\end{gathered}
$$

The percentages indicate the probability of a reaction occurring in a fast neutron spectrum at a typical fast reactor flux level. Thus, addition of Np-237 and Am-241 will have a detrimental effect on the "fissileness" of fresh fuel, but upon continued irradiation their daughter products will contribute positively to the "fissileness". Thus, if a reactor is started with a MA-bearing fuel, the material remaining after an irradiation campaign may have a higher "fissileness" than that of an equivalently irradiated fuel without initial MAisotopes in it.

\section{Introduction of the GFR600 Design}

The reactor investigated in the present work is GFR600, a 600 MWth Gen IV Gas Cooled Fast Reactor. GFR600 features a fast spectrum core with a high coolant fraction for safety, a carbide fuel in plate form (see Figure 1), all-ceramic components ( $\mathrm{SiC}$ for cladding, wrapper tubes and structural components, $\mathrm{Zr}_{3} \mathrm{Si}_{2}$ as a reflector material), and high-temperature operation with an outlet temperature up to $850^{\circ} \mathrm{C}$. The standard fuel is a mixture of UC and $\mathrm{PuC}(16 \%-18 \% \mathrm{Pu})$. Some basic core parameters are given in Table 2. Electrical output is 300 MWe (50\% efficiency). Calculations were performed replacing up to $10 \%$ of the UC with an MA-carbide compound. The isotopic vectors of the $\mathrm{Pu}$ and MA mixture are given in Tables 3 and 4. The isotopic vectors represent an average compositions for $\mathrm{Pu}$ and MA from spent LWR fuel as they will be available in France from $2016[8,9]$. These compositions were adopted as reference compositions for the present work. The MA is mixed homogeneously with the fuel, that is, in the fresh fuel the percentage of MA is the same everywhere; there are no special "transmutation assemblies".

Depletion calculations were performed using an in-house code package based on SCALE4.4a [10], using a homogenized 1D cylindrical reactor model. A special fast-reactor cross section library was used (175 groups, VITAMIN$\mathrm{J}$ [11]), as well as an updated ORIGEN-S library for transmutation calculations [12]. A three-batch fuel zoning was used. Because the 1D model is rather simple, and because it is generally accepted that SCALE is not the best simulation package for fast reactors, a benchmark was made with our STREP partners CIRTEN, who used the 3D code MONTEBURNS [13] in which the fuel plates were simulated individually. The results of this comparison show satisfactory

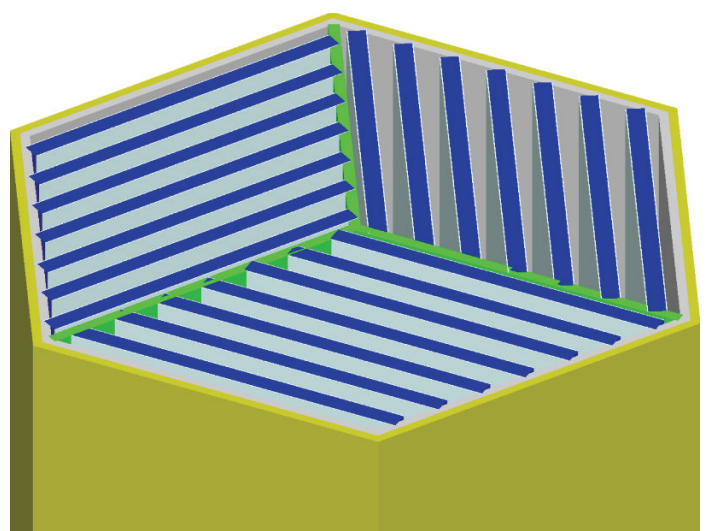

FIGURE 1: GFR600 fuel assembly. Each assembly contains 21 fuel plates and a central restraining device. All components are made of $\mathrm{SiC}$.

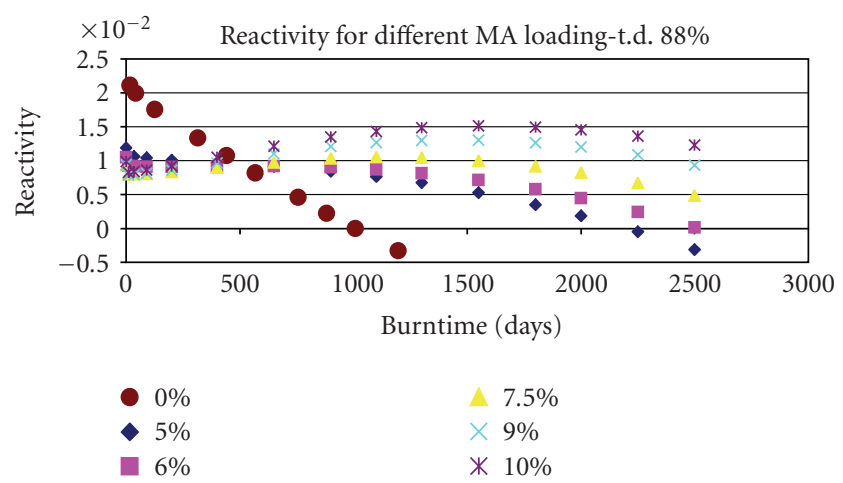

FIGURE 2: The reactivity for different MA loadings. The reactivity swing decreases for increased MA loading. For an MA loading above $6 \%$, the reactivity increases during the irradiation.

agreement between the $1 \mathrm{D}$ and $3 \mathrm{D}$ calculations as far as mass-flows of materials were concerned. Because of the short calculation time compared to the MONTEBURNS calculations, it was chosen to use the 1D model for the present calculations. Details of the benchmark calculations are reported in [14].

\section{Results for Single-Cycle Irradiations}

The first calculations were done on one irradiation cycle. The MA fraction was allowed to vary between $0 \%$ and $10 \%$, while the porosity of the fuel was reduced from $15 \%$ to $12 \%$ to offset the lower reactivity of the MA fuel. The effect on $k_{\text {eff }}$ is illustrated in Figure 2. The reference fuel $(0 \% \mathrm{MA})$ is designed to allow an irradiation interval of 1300 days, resulting in a burnup of some 5\% FIMA. With extra MA, the initial $k_{\text {eff }}$ of the fuel is lower, but the reactivity swing is lower, becoming positive if the MA loading is larger than $6 \%$, resulting in the potential of much longer irradiation intervals. The effect of transmutation of absorbing isotopes to fissile isotopes in the MA mixture as described earlier is evident. An irradiation interval of 2500 days was chosen as the reference for MA-containing fuel, 
TABLE 2: Core parameters for GFR-600 design.

\begin{tabular}{|c|c|c|c|}
\hline \multicolumn{4}{|c|}{ Reactor core parameters } \\
\hline Unit power & 600 MWth & Height & $1.95 \mathrm{~m}$ \\
\hline Average power density & $103 \mathrm{MW} / \mathrm{m}^{3}$ & Diameter & $1.95 \mathrm{~m}$ \\
\hline He average pressure & 70 bar & Ratio fuel/struct/cool & $35 \% / 10 \% / 55 \%$ \\
\hline Fuel element type & Plate & Refl. material & $\mathrm{Zr}_{3} \mathrm{Si}_{2}$ \\
\hline \multicolumn{4}{|c|}{ Subassembly design, fuel composition } \\
\hline Plates per S/A & 21 & Vol.\% SiC & $30 \%$ \\
\hline Fuel plates per rhom. & 7 & Vol.\% fuel & $70 \%$ \\
\hline Fuel S/A in core & 112 & Pu content & $16 \%$ \\
\hline Specific power & $40 \mathrm{~W} / \mathrm{gHM}$ & UPuC density & $13.6 \mathrm{~g} / \mathrm{cm}^{3}$ \\
\hline Core volume & $5.8 \mathrm{~m}^{3}$ & SiC density & $3.16 \mathrm{~g} / \mathrm{cm}^{3}$ \\
\hline Fuel mass & 16 tons & Fuel porosity & $15 \%-12 \%$ \\
\hline \multicolumn{4}{|c|}{ Temperatures $\left[{ }^{\circ} \mathrm{C}\right]$} \\
\hline $\mathrm{T}_{\text {core in }}$ & 480 & Max fuel temperature & $<1200$ \\
\hline $\mathrm{T}_{\text {core out }}$ & 850 & Max clad temperature & 1000 \\
\hline Fuel temperature & 990 & Coolant temperature & 665 \\
\hline Clad temperature & 665 & Reflector temperature & 565 \\
\hline
\end{tabular}

TABle 3: Isotopic vector of the plutonium, corresponding to the average plutonium expected to be available in France from 2016 [8].

\begin{tabular}{lc}
\hline $\mathrm{Pu}-238$ & $2.70 \%$ \\
$\mathrm{Pu}-239$ & $56.00 \%$ \\
$\mathrm{Pu}-240$ & $25.90 \%$ \\
$\mathrm{Pu}-241$ & $7.40 \%$ \\
$\mathrm{Pu}-242$ & $7.30 \%$ \\
$\mathrm{Am}-241$ & $0.70 \%$ \\
\hline
\end{tabular}

TABle 4: Isotopic vector of the Minor Actinide mixture. This mixture represents an average composition expected to be available from 2016 in France [8].

\begin{tabular}{lc}
\hline $\mathrm{Np}-237$ & $16.86 \%$ \\
$\mathrm{Am}-241$ & $60.64 \%$ \\
$\mathrm{Am}-242 \mathrm{~m}$ & $0.32 \%$ \\
$\mathrm{Am}-243$ & $15.69 \%$ \\
$\mathrm{Cm}-242$ & $0.02 \%$ \\
$\mathrm{Cm}-243$ & $0.07 \%$ \\
$\mathrm{Cm}-244$ & $5.14 \%$ \\
$\mathrm{Cm}-245$ & $1.25 \%$ \\
$\mathrm{Cm}-246$ & $0.10 \%$ \\
\hline
\end{tabular}

resulting in a final burnup of around 9.9\% FIMA and a total electricity production of 18 TWhe. In a 5\% MA fuel, $260 \mathrm{~kg}$ of MA is destroyed for a core inventory of $800 \mathrm{~kg}$ MA $(-14.4 \mathrm{~kg} / \mathrm{TWh})$; in a $10 \%$ MA fuel $650 \mathrm{~kg}$ is destroyed for a core inventory of $1600 \mathrm{~kg}$ MA $(-36.1 \mathrm{~kg} / \mathrm{TWhe})$. For comparison, in [2] some canonical numbers are given for the production of MA in PWRs per TWhe: $+3.2 \mathrm{~kg} / \mathrm{TWh}$ for a PWR using UOx fuel, and $+22.5 \mathrm{~kg} /$ TWhe for a PWR using MOx fuel. Thus, one GFR600 could support several PWRs if UOx fuel is used, and GFR600 can help in MA-management during the switch from a PWR-based to a fast-reactor-based fuel cycle. Furthermore, all MA loaded into the GFR600 will not go to a repository.

In Figure 3 the effect on the value of $\beta_{\text {eff }}$ is illustrated (calculated with the VAREX-code [15]). As expected, $\beta_{\text {eff }}$ decreases with increasing MA content. Two reasons for this effect can be found. One is the fact that the delayed neutron fraction in general decreases with increasing proton number, thus fissions in MA isotopes release less delayed neutrons. The second reason is neutron capture (mainly due to Am241). Neutron capture generally increases with decreasing neutron energy, and since delayed neutrons are born at a lower energy than fission neutrons, they are preferentially removed. Both these effects result in a lower effective delayed neutron fraction. In Figure 4 is illustrated the reactivity expressed in dollars during the irradiation cycle. It is seen that the reactivity swing is within a narrow bandwidth of about $3 \$$ for $5 \%$ and $10 \% \mathrm{MA}$ in the fuel. This is advantageous from a control point of view.

In Figure 5 is shown the fuel temperature coefficient (FTC) for the various fuel compositions, calculated as

$$
\mathrm{FTC}=\frac{k\left(T_{0}+\Delta T\right)-k\left(T_{0}\right)}{k\left(T_{0}\right)} \frac{1}{\Delta T} .
$$

The FTC is badly affected by the increase of the MA content, going from about $-1 \mathrm{pcm} / \mathrm{K}$ for the standard fuel to about $-0.35 \mathrm{pcm} / \mathrm{K}$ for the $10 \% \mathrm{MA}$ fuel. A fully satisfactory explanation for this effect has not yet been found, and more refined methods will be needed in this area. The void coefficient was calculated between fully pressurized ( $7 \mathrm{MPa})$ and at atmospheric pressure. The result is given in Table 5 . The void coefficient generally increases with increasing MA content. This can be explained as follows: the helium is neutronically almost inert, so its presence or absence should not influence the reactivity of the reactor. But the helium does introduce a little bit of moderation, thus upon voiding the spectrum will become harder, leading to higher neutron production 


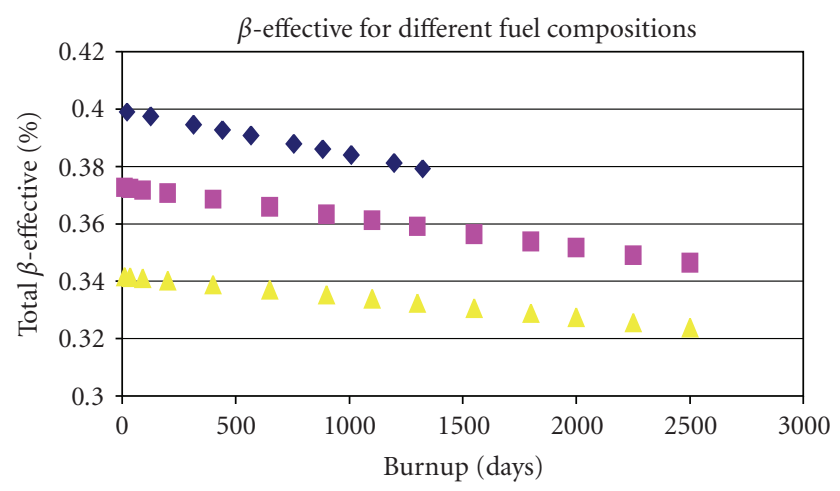

- $0 \% \mathrm{MA}$

- 5\% MA

A $10 \% \mathrm{MA}$

FIgure 3: The effective delayed neutron fraction decreases by $15 \%$ when the MA-fraction increases from $0 \%$ to $10 \%$.

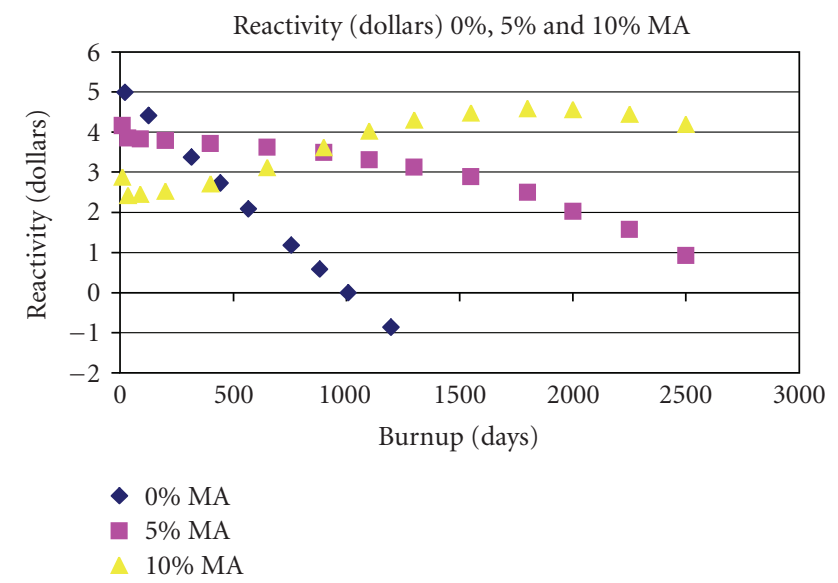

FIGURE 4: The reactivity for different MA loadings expressed in dollars. Note that a very long irradiation interval can be achieved with a very low reactivity swing.

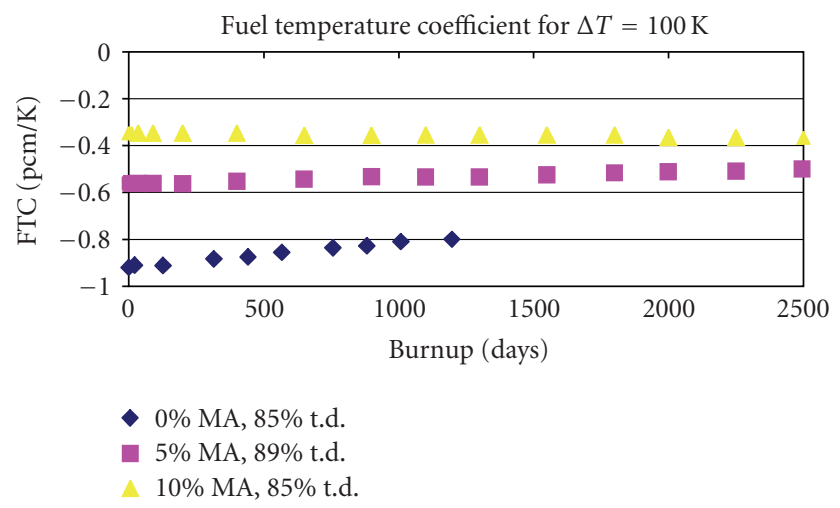

FIgURE 5: The fuel temperature coefficient as a function of MAfraction in the fuel.
TABLE 5: Void coefficient as a function of MA-loading in the core, in dollars between fully pressurized and atmospheric pressure.

\begin{tabular}{lc}
\hline MA\% & VC [\$] \\
\hline $0 \%$ & +4.23 \\
$5 \%$ & +5.29 \\
$10 \%$ & +6.41 \\
\hline
\end{tabular}

per fission ( $\eta$ increases with energy). Furthermore, many of the MA isotopes are threshold fissioners, and thus harder spectrum will increase the fission rate in the reactor. At the same time, the reduction of scattering increases the leakage, but since the reactor is laid out in a minimum leakage configuration $(H / D=1)$, this effect is not very strong. Thus the increase of the void coefficient with increasing MA content is reasonable (but still undesirable).

Concluding, the addition of MA to the fuel will allow a burnup with a low reactivity swing, but at the expense of a worsening of the safety parameters, that is, addition of MA reduces the effective delayed neutron fraction and fuel temperature coefficient, while increasing the void coefficient. Despite the fact that GFR600 is small, it can destroy the MA from several PWRs using UOx fuel. With an MA destruction of $14.4 \mathrm{~kg} / \mathrm{TWhe}$, one GFR600 can support approximately 4 PWRs using UOx fuel (MA production $+3.2 \mathrm{~kg} / \mathrm{TWh}$ ). For a PWR using MOx fuel (MA production $+22.5 \mathrm{~kg} / \mathrm{TWhe}$ ), one or two of GFR600 would be needed, depending on the MA fraction in the GFR fuel.

\section{Results for Multirecyling Irradiations}

GFR600 is envisaged to run in a closed fuel cycle. As a result, no two successive fresh fuel compositions will be the same due to the accumulation of MA isotopes in the fuel. In the ideal case, addition of fertile material to the reprocessed fuel should suffice to make a new fuel load. During the cooling period prior to reprocessing the reactivity of the fuel changes, for example, reactivity is lost by the decay of $\mathrm{Pu}-241$ to Am-241. Three refueling scenarios were investigated. In each case, the cooling period is six years, and all HM material is used to make new fuel (reprocessing losses were assumed negligible).

(i) Refueling with Depleted Uranium (DU) only.

(ii) Refueling with a constant fraction of MA in the fresh fuel (MA).

(iii) Refueling with a constant reactivity weight of the fresh fuel (CW).

The reactivity weight of the fuel is defined as

$$
w(t)=\sum_{i=1}^{I} w_{i} N_{i}(t)
$$

where $N_{i}$ is the number density of isotope $i$, and $w_{i}$ is the corresponding reactivity weight according to (1). It is expected that the CW strategy most closely approximates 


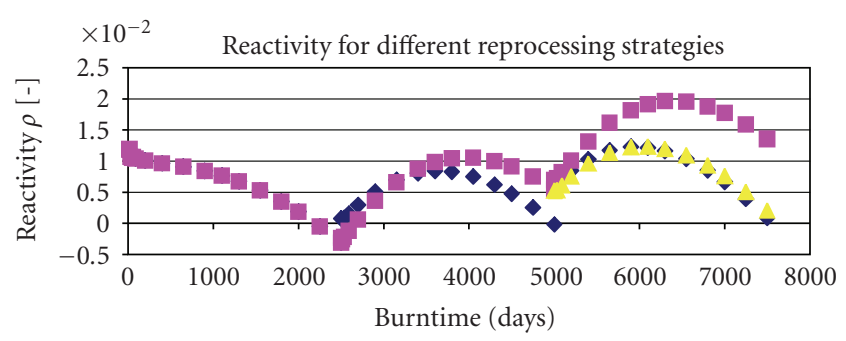

- DU-added

- Constant MA\%

$\triangle$ Constant fiss

FIgURE 6: For 3 subsequent fuel irradiations in a closed fuel cycle, the $k_{\text {eff }}$ as a function of time. The "Constant fiss." curve corresponds to the constant reactivity weight refueling strategy.

a truly closed fuel cycle, because each new fuel loading is similar to a previous one as far as the fuel reactivity is concerned. Three refuelings are simulated, spanning a total of some 40 years of reactor operation ( 7 years of irradiation, 6 years of cooling and a year of reprocessing and refabrication). One typical result is reported in Figure 6, for a 5\% MA loading in the fuel (more information is available in [14]). It is seen that keeping the MA content in the fuel constant increases the reactivity of the fuel over successive cycles due to transmutation of fertile to fissile isotopes. Refueling with DU only is also possible, because sufficient extra fissile material is being bred from the MA mixture. The CW case is similar to the DU case.

One of the typical results is that the reactivity swing follows a "parabola-like" curve for most fuels with a sufficient amount of MA. The CW refueling was shown to not always be possible, for example, if too much fissile material is bred during irradiation, the reactivity weight of the new fuel will be higher even if only DU is added. An investigation was done into the possibility of tuning the MAfraction added during reprocessing to obtain a target value of $k_{\text {eff }}$ at the end of the cycle and have a low reactivity swing. Several permutations of this strategy were calculated, and a typical result is given in Figure 7 , where the $k_{\text {eff }}$ is shown for successive irradiations (in these investigations, the standard irradiation time of 1300 days is used, but the MA is allowed to vary between cycles). In this case, the target was set at $k_{\text {eff,final }}=1.05$. The first cycle uses the standard $0 \% \mathrm{MA}$ fuel. In Figure 8 is given the amounts of MA added after each cycle. Thus, after the first cycle the target $k_{\text {eff }}$ is not achieved, and only MA is added to the fuel to increase the end-of-cycle $k_{\text {eff }}$ of the new fuel. The second cycle ends with a higher $k_{\text {eff }}$, so afterwards a mix of DU and MA is added. In the third cycle, the target $k_{\text {eff }}$ is obtained, and subsequently maintained by carefully choosing the correct amount of DU and MA to be added after each cycle.

Overall, addition of MA has positive effects on the possibility of obtaining a closed fuel cycle: fuel made from reprocessed material will have a higher reactivity with MA present in the fuel, and it is possible to tune the fraction of MA in the fuel for desired fuel performance. It is

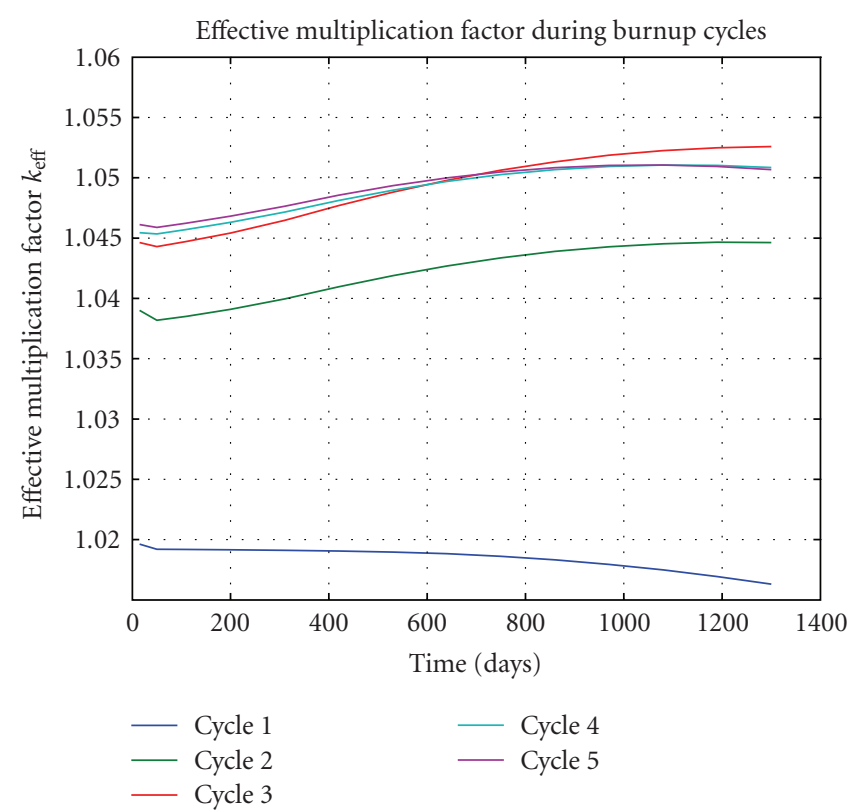

FIGURE 7: Succesive irradiation campaigns, changing the MAfraction added in reprocessing to achieve $k_{\text {eff,final }}=1.05$, starting from a $0 \% \mathrm{MA}$ fuel. From the third cycle, the objective is met.

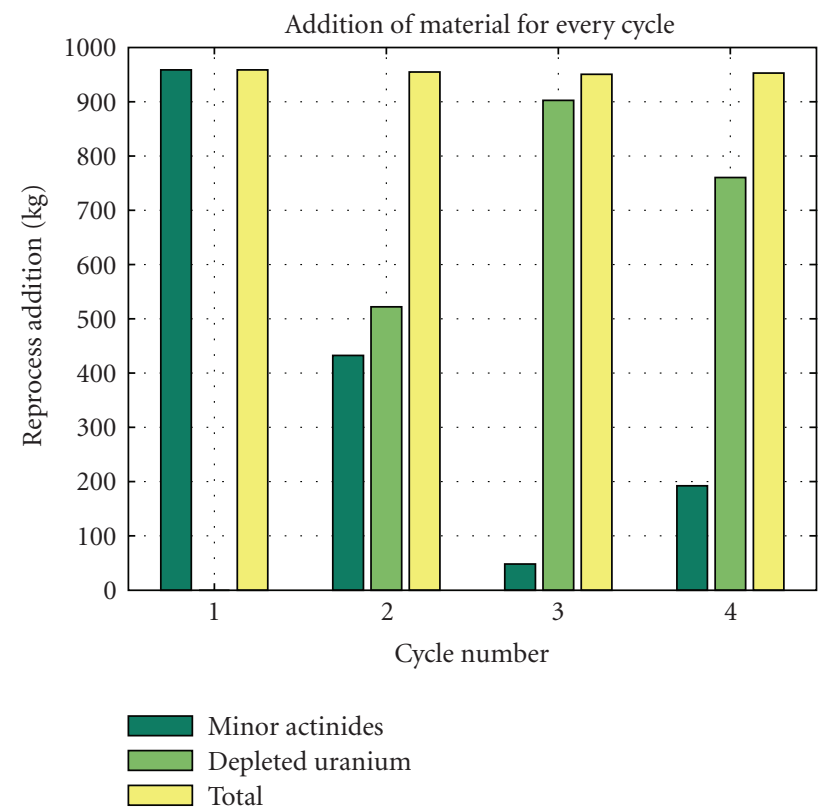

FIGURE 8: Amounts of MA and DU added to the fuel after each cycle, in order to make $k_{\text {eff,final }}=1.05$. In the first reprocessing, purely MA is added to increase the end-of-cycle $k_{\text {eff }}$ in the next irradiation campaign. In subsequent campaigns, a mix of MA and DU is used.

acknowledged that addition of MA is not a truly closed fuel cycle, but the amount of MA required is small, only a few percent of the total fuel mass. It is difficult to assign a support ratio to the multirecycling calculations, because there is no clear picture of the transition scenario when GFR600 will be introduced. 


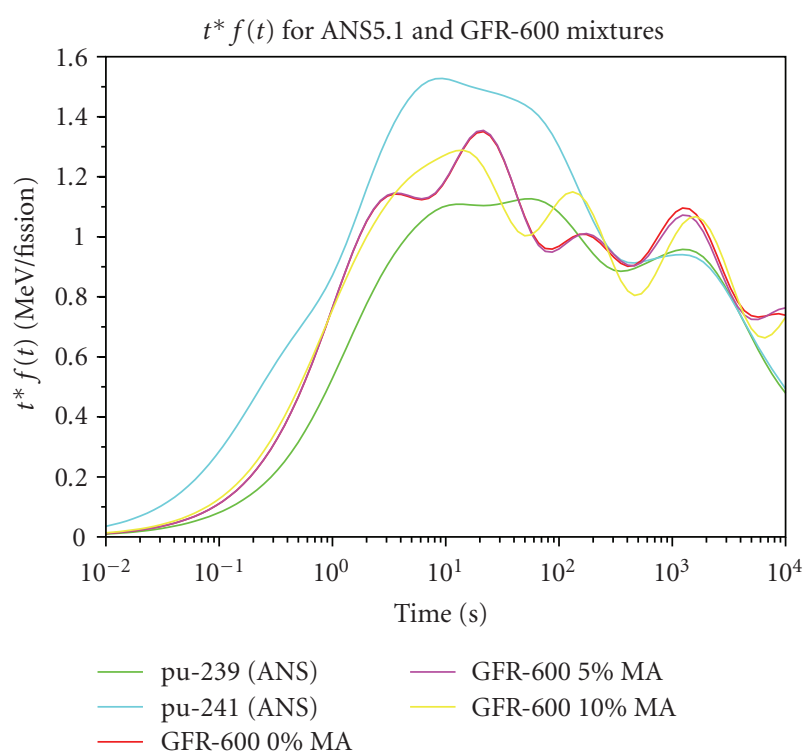

Figure 9: Plot of $t \cdot f(t)$ for the two plutonium isotopes in the ANS5.1 standard and for the 3 GFR-600 mixtures.

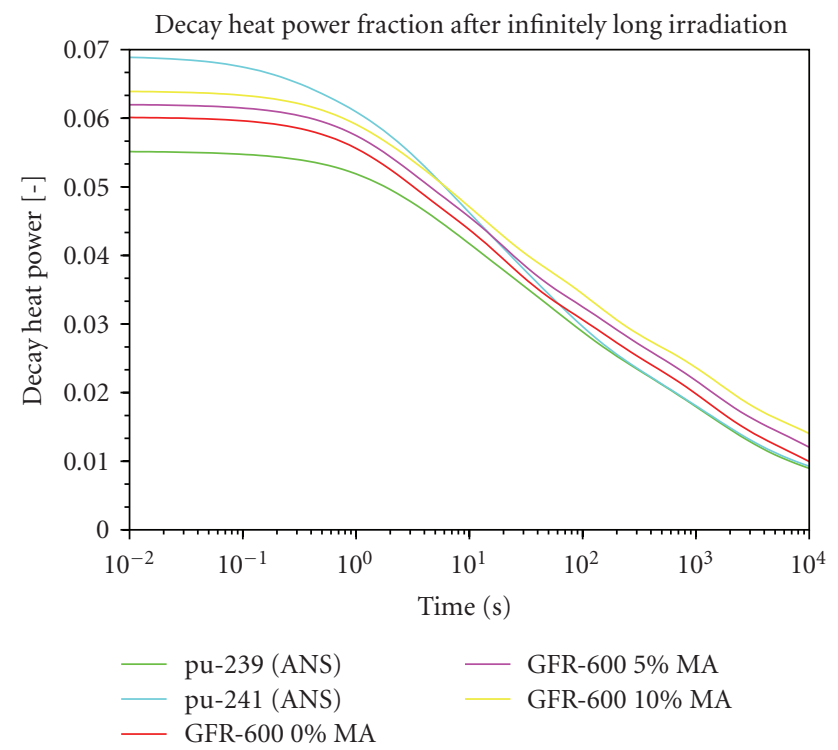

FIGURE 10: Decay power after an infinitely long irradiation period for the two plutonium isotopes present in the ANS5.1 standard and for the 3 GFR-600 mixtures (cf. (11)).

\section{Decay Heat Calculations}

One of the prime safety targets of the GFR600 design is to allow Decay Heat Removal (DHR) by natural convection under pressurized conditions. An accurate determination of the decay heat emanating from the fuel with various amounts of MA loading is thus important. For light water reactors, the amount of decay heat is commonly calculated based on a decay heat standard (such as the ANSI/ANS-5.1 standard [16] or the DIN standard [17]). These standards only take into account decay heat due to fission products. In reactors with high MA loading, the decay heat of the MA needs to be taken into account as well. The presence of MA in the core will increase the decay heat for long time scales. The applicability of the decay heat standards to GFR600 is limited. For these reasons, limited investigations were done of the decay heat in GFR600 with various MA loadings.

The decay power is commonly described as the time dependent power following one fission in isotope $j$ as

$$
f(t)=\sum_{k=1}^{K} \gamma_{j k} \exp \left(-\mu_{j k} t\right)
$$

in units of $\mathrm{MeV} \cdot \mathrm{s}^{-1}$ per fission. This formulation assumes that all fission products can be grouped into $K$ fission product groups (usually between 23 and 33). Each group has a decay constant $\mu_{j k}$, and a contribution $\gamma_{j k}$ to the total decay power. The function $f(t)$ is an impulse response and can be extended to an arbitrary fission rate history $\psi(t)$ by convolution to find the decay heat at time $t_{0}$ :

$$
P_{d}\left(t_{0}\right)=\int_{0}^{t_{0}} \psi(t-\tau) f(\tau) d \tau .
$$

To calculate the decay heat after shutdown, (9) should be solved with knowledge of $\psi(t-\tau)$. This method is commonly used in thermal-hydraulic codes. The "worst case" decay heat from a single isotope can be calculated as follows. Assume a unit fission rate present over a time interval $I$, and evaluate the decay heat power at time $t$ after shutdown of the fission source. Then, (9) can be rewritten for nuclide $j$ as

$$
\begin{aligned}
P_{d}(t) & =\int_{t}^{t+I} \sum_{k=1}^{K} \gamma_{j k} \exp \left(-\mu_{j k} t\right) d t \\
& =\left[\sum_{k=1}^{K} \frac{-\gamma_{j k}}{\mu_{j k}} \exp \left(-\mu_{j k} t\right)\right]_{t}^{t+I} \\
& =\sum_{k=1}^{K} \frac{\gamma_{j k}}{\mu_{j k}} \exp \left(-\mu_{j k} t\right)\left[1-\exp \left(-\mu_{j k} I\right)\right] .
\end{aligned}
$$

If the irradiation interval $I$ is infinitely long, the second term on the RHS equals one and the time dependent decay heat after shutdown is found as:

$$
P_{d}(t)=\sum_{k=1}^{K} \frac{\gamma_{j k}}{\mu_{j k}} \exp \left(-\mu_{j k} t\right) .
$$

For three fuel compositions, that is, $0 \%, 5 \%$ and $10 \%$ MA, the decay heat for GFR-600 was calculated using ORIGEN-S [18] with special fast reactor data libraries based on JEF and EAF data [12]. ORIGEN-S calculates the decay heat power density in the fuel elements. The result is normalized to the total reactor power, giving a curve of decay heat power as a percentage of nominal reactor power after shutdown. The parameters for the model were estimated by fitting the following equation to the curves:

$$
P_{d}(t)=\sum_{k=1}^{11} \alpha_{k} \exp \left(-\lambda_{k} t\right)
$$


The parameters found from the fit can be readily converted to the form of (11) by introducing new parameters $\alpha_{k}^{\prime}$ such that $\alpha_{k}^{\prime} / \lambda_{k}=\alpha_{k}$. The parameter sets are subsequently converted to units of $\mathrm{MeV}$ per fission using the total removable fission power, which is a number calculated by ORIGEN-S and available in the ORIGEN-S output. In Figures 9 and 10 illustrations are given of $t f(t)$ and $P_{d}(t)$ (as a percentage of the total removable energy per fission), for GFR600 with $0 \%, 5 \%$, and 10\% MA loading. For comparison, the decay heat due to thermal fission in $\mathrm{Pu}$ 239 and $\mathrm{Pu}-241$ as calculated using the ANS standard, is also illustrated. From these results, one can make the following observations.

(i) As a generality, the decay heat in GFR600 is in line with what is to be expected from a system where $\mathrm{Pu}$ 239 and $\mathrm{Pu}-241$ are the main fissioning isotopes, for example, the initial amount of decay heat is between $\mathrm{Pu}-239$ and $\mathrm{Pu}-241$.

(ii) Given that the ORIGEN-S results for GFR600 are in line with the ANS5.1 standard for short cooling times in Figure 9 increases confidence in the results (see [19] for a discussion of decay heat calculations in ORIGEN-S for short cooling times).

(iii) For long cooling times, the GFR600 decay heat is much larger than the ANS predictions. This is where one sees the effect of the decay heat due to nonfission products, such as $\alpha$-decay of MA isotopes, which is not taken into account in the ANS standard.

(iv) The GFR600 decay heat is significantly higher than the ANS predicted values, especially for long cooling times. For short cooling times, the amount of decay heat is as predicted by the ANS standard for the main fissioning isotopes in GFR600 fuel. As a result, a "conservative" estimation based on "ANS+10\%", which is sometimes proposed, may be overly pessimistic for short cooling times and not pessimistic enough for long cooling times.

\section{Conclusions and Recommendations}

In this paper a general overview is given of a typical fuel cycle for a Gen IV Gas Cooled Fast Reactor, using a closed fuel cycle. This reactor concept focuses on sustainability, by efficient resource utilization and minimizing waste. The Gen IV GCFR is designed with a strong focus on (passive) safety. Results were reported on the effects of admixing extra Minor Actinide isotopes to the fuel of GFR600, a $600 \mathrm{MWth}$ GCFR. The results of these investigations are that addition of MA to the fuel will reduce the reactivity swing and increase the irradiation interval, due to the transmutation of fertile MA isotopes into fissile isotopes. A high burnup may be achieved (about 10\% FIMA) with a relatively low reactivity swing over the cycle (about $4 \$$ ). A low reactivity swing is generally desirable from a safety and control point of view. Addition of MA will lower the reactivity of the fresh fuel, but subsequent transmutation of $\mathrm{MA}$ isotopes can in fact increase the reactivity of the new fuel made from recycled materials. Thus the presence of MA increases the range of possibilities for a closed fuel cycle. It was shown that MA addition can be used to tune the $k_{\text {eff }}$ over the irradiation cycle. Thus, for the fuel cycle the addition of MA to the fuel is beneficial. But there are disadvantages: the delayed neutron fraction is smaller, the fuel temperature coefficient is smaller, and the void coefficient, measured in \$, is higher. Only a more detailed thermal-hydraulic investigation of the primary and secondary circuits can clarify if the safety parameters are still acceptable. Initial calculations of decay heat from the MA-bearing fuel indicate that for short cooling times the decay heat is in line with existing decay heat standards, but for long cooling times $\left(10^{4} \mathrm{~s}\right)$ the decay heat is significantly larger.

Recommendations for further research include the following: in the presented work, the production of helium gas in the fuel due to $\alpha$-decay of the MA was not taken into account. However, the pressure caused by the helium could become a limiting factor for the fuel design. The plate fuel design adopted in this study is still speculative, and several improvements have already been identified [20]. The reported decrease of the Fuel Temperature Coefficient requires a fundamental explanation. A lack of cross section and resonance data for the MA isotopes may be the cause, but only a detailed investigation can shed more light. The radioactivity, and related to that the feasibility of reprocessing, needs to be ascertained for the MA-bearing fuel compounds. Open questions in this area concern the availability of MA separation technology, the neutron emission from the fuel after multiple irradiation cycles, the feasibility and safety of carbide fuel reprocessing, and the metallurgical and ceramics implications of $10 \% \mathrm{MA}$ addition.

\section{Acknowledgments}

The authors would like to acknowledge the support of the European Commission through the GCFR STREP program, carried out under Contract no. 012773 (FI6O) within the EURATOM 6th Framework Program from March 1, 2005 to February 28, 2009. The main part of the work reported here was carried out when W. van Rooijen was employed by Delft University of Technology in The Netherlands. The authors acknowledge the work of their students G. J. van Gendt and D. I. van der Stok.

\section{References}

[1] U.S. DOE Nuclear Energy Research Advisory Committee and the Generation IV International Forum, "A technology roadmap for Generation IV nuclear energy systems," December 2002, http://gif.inel.gov/roadmap/.

[2] Commissariat à l'Énergie Atomique, "Les déchets radioactifs à haute activité et à vie longue-recherches et résultats axe 1: séparation et transmutation des radionucléides à vie longue," December 2005.

[3] W. F. G. van Rooijen, J. L. Kloosterman, T. H. J. J. van der Hagen, and H. van Dam, "Definition of breeding gain for the closed fuel cycle and application to a gas-cooled fast reactor," 
Nuclear Science and Engineering, vol. 157, no. 2, pp. 185-199, 2007.

[4] M. Salvatores, "Fast reactor calculations," in Handbook of Nuclear Reactor Calculations, vol. 3, pp. 263-363, CRC Press, Boca Raton, Fla, USA, 1986.

[5] SCALE, A Modular Code System for Performing Standardized Computer Analyses for Licensing Evaluations, Vols I-III, Oak Ridge National Laboratory, Oak Ridge, Tenn, USA, ORNL/TM-2005/39, Version 5.1, Available from Radiation Safety Information Computational Center at Oak Ridge National Laboratory as CCC-732, 2006.

[6] G. Sengler, F. Forêt, G. Schlosser, R. Lisdat, and S. Stelletta, "EPR core design," Nuclear Engineering and Design, vol. 187, no. 1, pp. 79-119, 1999.

[7] J. Rouault, A. Judd, J. C. Lefèvre, and G. Mühling, "CAPRA preliminary feasibility studies, synthesis and conclusions," Tech. Rep., CEA, Cedex, France, 1994.

[8] J. C. Bosq, "Personal communication," CEA Cadarache, March 2005.

[9] K. D. Weaver, T. C. Totemeier, D. E. Clark, et al., "Gen IV nuclear energy systems, gas-cooled fast reactor (GFR). FY04 annual report," Tech. Rep. INEEL/EXT-04-02361, Idaho National Engineering and Environmental Laboratory, Idaho Falls, Idaho, USA, September 2004.

[10] SCALE, A Modular Code System for Performing Standardized Computer Analyses for Licensing Evaluation, Oak Ridge National Laboratory, Oak Ridge, Tenn, USA, NUREG/CR0200, version 4.4a, 2000.

[11] R. E. MacFarlane and D. W. Muir, "The NJOY nuclear data processing system," Tech. Rep. Version 91 LA-12740-M, Los Alamos National Laboratory, Los Alamos, NM, USA, October 1994.

[12] J. E. Hoogenboom and J. L. Kloosterman, "Generation and validation of ORIGEN-S libraries for depletion and transmutation calculations based on JEF2.2 and EAF3 basic data," Nuclear Engineering and Design, vol. 170, no. 1-3, pp. 107-118, 1997.

[13] D. L. Poston and H. R. Trellue, "User's manual, version 2.0 for MONTEBURNS version 1.0,” Tech. Rep. LA-UR-99-4999, Los Alamos National Laboratory, Los Alamos, NM, USA, 1999.

[14] W. F. G. van Rooijen, J. L. Kloosterman, G. van Gendt, et al., "Actinide transmutation in GFR (option 1): final report, 2007," Tech. Rep. GCFR-STREP D31, European Commission Sixth Framework Program, Work Package 1.1 Task 4, 2008.

[15] J. L. Kloosterman and J. C. Kuijper, "VAREX, a code for variational analysis of reactivity effects: description and examples," in Proceedings of the ANS International Topical Meeting on Advances in Reactor Physics (PHYSOR '00), ANS, Seoul, Korea, October 2000.

[16] ANSI, "Decay heat power in light water reactors," Tech. Rep. ANS-5.1-1994. W2004, ANSI/ANS, La Grange Park, Ill, USA, 2004.

[17] DIN, "Berechnung der Nachzerfallsleistung der Kernbrennstoffe von Leichtwasserreaktoren; Nichtrezyklierte Kernbrennstoffe," Tech. Rep. DIN 25463-1, Deutsches Institut für Normung e. V., Berlin, Germany, May 1990.

[18] I. C. Gauld, O. W. Hermann, and R. M. Westfall, ORIGENS: SCALE System Module to Calculate Fuel Depletion, Actinide Transmutation, Fission Product Buildup and Decay, and Associated Radiation Source Termes, Oak Ridge National Laboratory, Oak Ridge, Tenn, USA, 2005.
[19] I. Gauld, "Validation of ORIGEN-S decay heat predictions for LOCA analysis," in Proceedings of the ANS International Topical Meeting on Advances in Reactor Physics (PHYSOR '06), pp. 110, ANS, Vancouver, Canada, September 2006.

[20] N. Chauvin, J.-Y. Malo, J.-C. Garnier, et al., "GFR fuel and core pre-conceptual design studies," in Proceedings of the International Conference on Advanced Nuclear Fuel Cycles and Systems (GLOBAL '07), pp. 423-433, ANS, Boise, Idaho, USA, September 2007. 

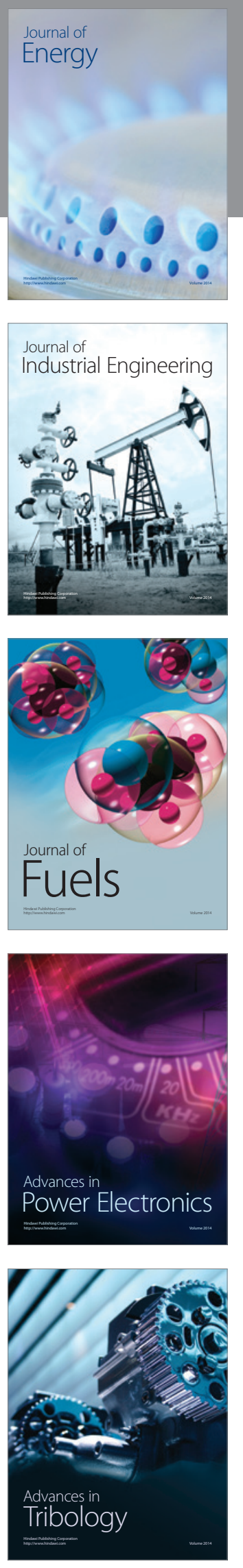
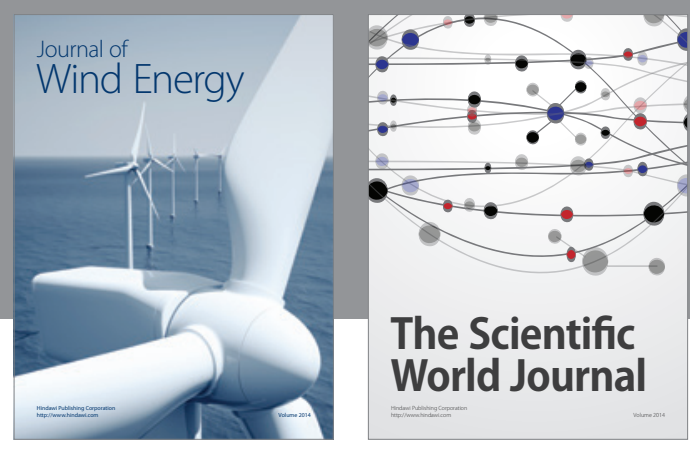

The Scientific World Journal

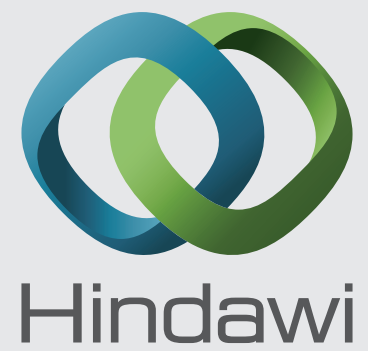

Submit your manuscripts at http://www.hindawi.com
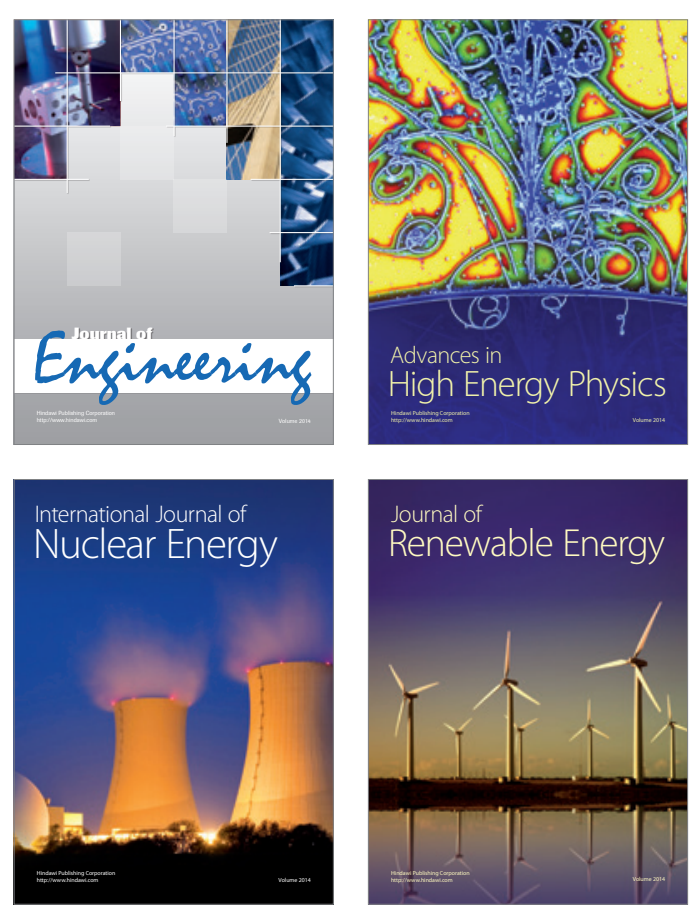

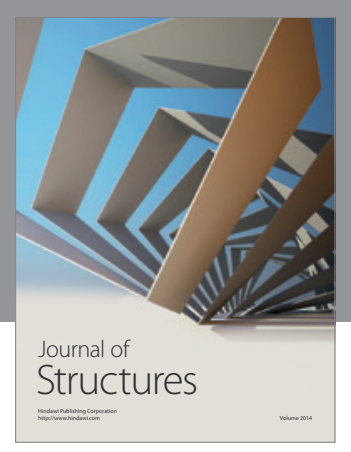

Rotating
Mechinery
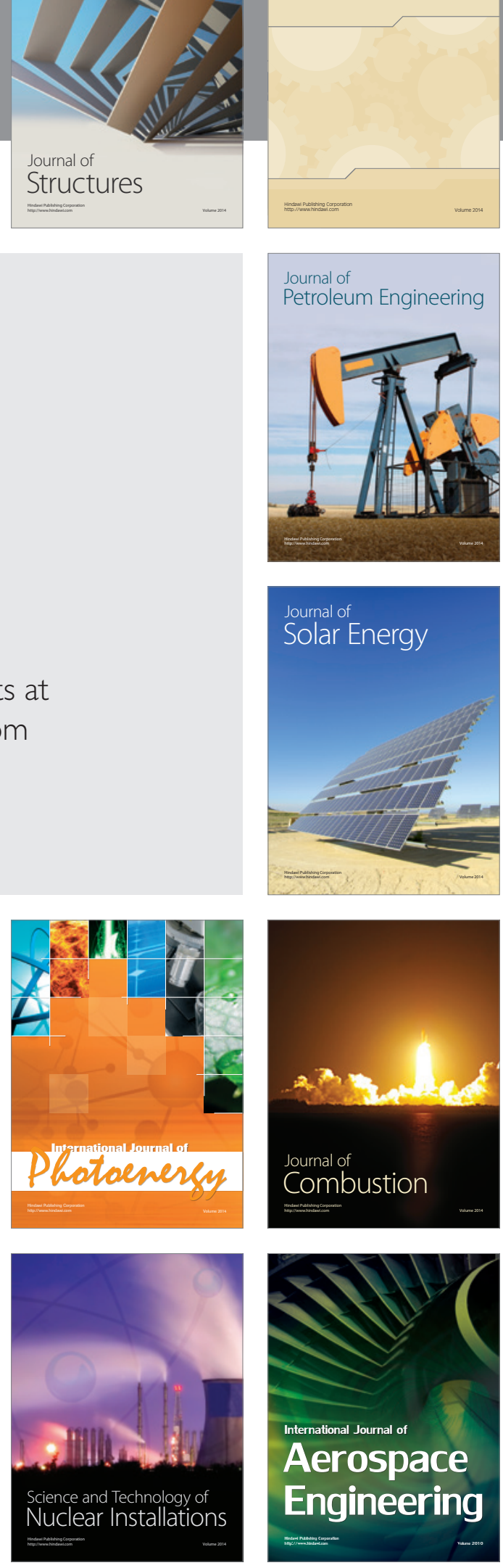